\title{
Reducing uncertainties associated with filter-based optical measurements of light absorbing carbon particles with chemical information
}

\author{
J. E. Engström ${ }^{1,2}$ and C. Leck $^{1}$ \\ ${ }^{1}$ Stockholm University, Department of Meteorology (MISU), Stockholm, Sweden \\ ${ }^{2}$ Swedish Meteorological and Hydrological Institute, Norrköping, Sweden
}

Received: 18 February 2010 - Published in Atmos. Meas. Tech. Discuss.: 25 March 2010

Revised: 14 June 2011 - Accepted: 12 July 2011 - Published: 2 August 2011

\begin{abstract}
The presented filter-based optical method for determination of soot (light absorbing carbon or Black Carbon, BC) can be implemented in the field under primitive conditions and at low cost. This enables researchers with small economical means to perform monitoring at remote locations, especially in the Asia where it is much needed.

One concern when applying filter-based optical measurements of BC is that they suffer from systematic errors due to the light scattering of non-absorbing particles co-deposited on the filter, such as inorganic salts and mineral dust. In addition to an optical correction of the non-absorbing material this study provides a protocol for correction of light scattering based on the chemical quantification of the material, which is a novelty. A newly designed photometer was implemented to measure light transmission on particle accumulating filters, which includes an additional sensor recording backscattered light. The choice of polycarbonate membrane filters avoided high chemical blank values and reduced errors associated with length of the light path through the filter.

Two protocols for corrections were applied to aerosol samples collected at the Maldives Climate Observatory Hanimaadhoo during episodes with either continentally influenced air from the Indian/Arabian subcontinents (winter season) or pristine air from the Southern Indian Ocean (summer monsoon). The two ways of correction (optical and chemical) lowered the particle light absorption of $\mathrm{BC}$ by 63 to $61 \%$, respectively, for data from the Arabian Sea sourced group, resulting in median BC absorption coefficients of 4.2 and $3.5 \mathrm{Mm}^{-1}$. Corresponding values for the South Indian Ocean data were 69 and $97 \%\left(0.38\right.$ and $\left.0.02 \mathrm{Mm}^{-1}\right)$. A
\end{abstract}

Correspondence to: J. E. Engström (erik.engstrom@smhi.se) comparison with other studies in the area indicated an overestimation of their BC levels, by up to two orders of magnitude. This raises the necessity for chemical correction protocols on optical filter-based determinations of BC, before even the sign on the radiative forcing based on their effects can be assessed.

\section{Introduction}

Of the many identified and potential effects of atmospheric aerosol particles on climate (Forster et al., 2007), those of dark soot particles are the most uncertain for several reasons. Firstly, our understanding of the atmospheric life cycle of soot is incomplete with possible changes of the surface character of soot from hydrophobic near combustion sources to wettable or even hydrophilic during its dispersion and ageing in the atmosphere, promoting its removal by wetdeposition. Secondly, sampling and analytical techniques concerning soot and its effects are far from satisfactory, in particular if its multi-component and multi-phase nature is considered. Thirdly, there are no generally agreed physicalchemical definitions of soot and no established standards or reference materials.

Soot is referred to as light absorbing carbon or black carbon (BC) when determined with techniques that are based on the optical property of soot being a strong absorber of light in the visible wavelength region (Bond et al., 1999; Petzold et al., 2005). Several extensive reviews concerned with optical measurements of $\mathrm{BC}$ have been published in the literature (Clarke et al., 1987; Horvath, 1993; Sheridan et al., 2005; Bond and Bergstrom, 2006; Hitzenberger et al., 2006). 
One worry when applying optical measurements of ambient $\mathrm{BC}$ concerns possible interferences with non-elemental carbon compounds. Carbon containing aerosol particles that absorb light can be regarded as a continuous spectrum of compounds, with $\mathrm{BC}$ as a strong absorber at $550 \mathrm{~nm}$ wavelength and organic carbon, OC, (originating from biological processes such as low temperature oxidation) absorbing towards shorter wavelengths in UV which gives the compounds a brown or yellow color. As OC does not absorb strongly where $\mathrm{BC}$ normally is measured its presence should be of minor concern. However, it has also been shown that large amounts of OC are collected as liquid drops, rather than as solid particles, which can cause errors in the measured light absorption (Subramanian et al., 2007).

Light absorption (abs) can be estimated if the extinction (ext) and scattering (sca) by BC is known (Eq. 1). The extinction can be measured as the ratio of incoming light $\left(I_{\text {in }}\right)$ and transmitted light $\left(I_{\text {trans }}\right)$.

$\mathrm{ext}=\mathrm{sca}+\mathrm{abs}=\frac{I_{\text {in }}}{I_{\text {trans }}}$.

By monitoring the change in transmitted light through a filter, estimates of the absorption are possible. Commonly used filter types are made of glass or quartz fibers or consist of porous membranes.

The most reliable (according to Andreae and Gelencser, 2006) filter based optical method used is the Multiple Angle Absorption Photometer (MAAP) (Petzold et al., 2005) that measures both the transmission and scattering at several wavelengths. Another commonly used instrument is the Particle Soot Absorption Photometer (PSAP) (Bond et al., 1999) which does not record light scattering by the deposited particles.

The above well-established approaches for filter-based optical measurements of BC suffer however from systematic errors due to the optical effects of non-absorbing or lowabsorbing particles, such as inorganic constituents (e.g. sulfate, nitrate, mineral dust, and sea salt), in the sample which relates to the dependence of aerosol light scattering on the chemical composition. To correct for these systematic errors the MAAP instrument has the advantage of continuously measuring light scattered back from the sample in two angles but without any direct information on chemical composition of the non-absorbing material. The PSAP instrument compensates for its lack of recording scattered light in a simplified way by applying a constant correction (Bond et al., 1999) and thus not accounting for changing aerosol composition.

In an attempt to further reduce errors dominated by the optical effects of non-absorbing particles this study will in addition to determine the scattered light provide a chemical quantification of the inorganic fraction of the non-absorbing material. A photometer measured light transmission and scattering at $528 \mathrm{~nm}$ on particulate samples accumulated on polycarbonate membrane (PCMB) filters. The PCMB filters were selected to avoid high chemical blank values characteristic for the otherwise commonly used glass fiber filters (Bond et al., 1999).

Additional errors are associated with the filter itself (referred to as filter effects in Sect. 2.3.1), which will affect the length of the light path through the filter. This can lead to multiple light paths resulting in an overestimation of the recorded light absorption. Both the MAAP and PSAP methods apply protocols to correct for errors associated with filter effects based on artificial and ambient sample characterizations of the absorption (Petzold et al., 2005; Bond et al., 1999). A similar protocol but specifically characterized for the application of PCMB filters was used in this study. The choice of PCMB filters instead of glass fiber filter is also advantageous since the particles are deposited on the filter surface and not further embedded in the glass filter texture.

The methods of corrections derived in this study were applied to ambient aerosol samples collected at the Maldives Climate Observatory Hanimaadhoo (MCOH). The samples were collected during episodes with both continental influenced air from the Indian/Arabian subcontinents and pristine air from the Southern Indian Ocean.

\section{Measuring site and methods}

\subsection{Maldives Climate Observatory Hanimaadhoo (MCOH)}

$\mathrm{MCOH}$ is located on the northern point of Hanimaadhoo, an island in the northern part of the Maldives (longitude $73^{\circ} 10^{\prime} 59^{\prime \prime}$ E latitude $6^{\circ} 46^{\prime} 34^{\prime \prime} \mathrm{N}$ ), and stretching $4 \mathrm{~km}$ north to south and $1 \mathrm{~km}$ east to west. The Maldives consist of an archipelago of nearly 2000 coral atolls covering $800 \mathrm{~km}$ north to south in the Indian Ocean at a distance of between 200 and $1200 \mathrm{~km}$ southwest of the southern cape of the Indian subcontinent (Fig. 1). The topography of the islands is low and no natural point rises above $3 \mathrm{~m}$. The islands therefore have a very small effect on the atmospheric circulation and serve as good locations for atmospheric in situ measurements of air originating from either the Asian continent or the Southern hemisphere. Hanimaadhoo has a population of around 1200 and is free from influence by population centers and industries. The location of the observatory, at the northern cape of the island with ocean on three sides at most $100 \mathrm{~m}$ away, ensures that the prevailing wind comes from over the ocean. Thus the site has no significant local BC emissions upwind of the station, and the composition of the air and rain is dominated by the regional sources (Corrigan et al., 2006).

Air was sampled from a $15 \mathrm{~m}$ high tower where various sensors and the inlets for air sampling were mounted. A $15 \mathrm{~m}$ long stainless steel tube (diameter $20 \mathrm{~cm}$ ) led the sampled air down to the instruments with a laminar flow of $300 \mathrm{dm}^{3} \mathrm{~min}^{-1}$. The air inlet was equipped with a cyclone discarding supermicrometer particles, implying that only particles smaller than $10 \mu \mathrm{m}$ in equivalent aerodynamic 




Fig. 1. The location of the station $\mathrm{MCOH}$ in the Maldives (longitude $73^{\circ} 10^{\prime} 59^{\prime \prime} \mathrm{E}$, latitude $6^{\circ} 46^{\prime} 34^{\prime \prime} \mathrm{N}$ ).

diameter (EAD) passed. The aerosol instruments were installed at surface level in the building within a temperature and humidity controlled environment to avoid condensation of water inside the instruments due to a lower temperature (Corrigan et al., 2006). Inside the building aluminium tubing (diameter $15 \mathrm{~cm}$, concentric head) selected the air in the middle of the larger tube to avoid wall effects. Subsequently the airflow was distributed to the instruments. Depending on the expected ambient mass concentrations, $\mathrm{Nu}$ clepore ${ }^{\circledR}$ polycarbonate membrane (PCMB) filter $(0.4 \mu \mathrm{m}$ pore size, $37 \mathrm{~mm}$ diameter) samples were taken for 24 or $48 \mathrm{~h}$, through isokinetic take off lines from the main inlet pipe. Sampling flow was $2.0 \mathrm{dm}^{3} \mathrm{~min}^{-1}$ and a cyclone with a size cut of $D \mathrm{p}_{50}=2 \mu \mathrm{m}$ (excluding particles with an EAD larger than $2 \mu \mathrm{m}$ ) was mounted upstream of the sampler. The exposed filter surface was masked to $8 \mathrm{~mm}$ sampling diameter $\left(0.5 \mathrm{~cm}^{2}\right.$ area). The geometric configuration (Hansson et al., 1987) of the sample spot on the filter surface was used to optimize the analytical conditions (increase the signal to noise ratio) for the post-sampling analyses (BC and non-light absorbing particulate ionic mass) on the PCMB filters. Prior to analyses the PCMB filters were stored in filter cassettes, which were sealed with parafilm.

\subsection{Determination of light absorption and backscattering}

During stable condition back at the laboratory of the Department of Meteorology, Stockholm University (MISU), a newly developed photometer constructed in accord with the setup by Heintzenberg (1988), detected the attenuation of light transmitted through the particles that had accumulated on the PCMB Nuclepore ${ }^{\circledR}$ filter. The light source was a light emitting diode (LED) operating at $528 \mathrm{~nm}$. Light transmission through the sample spot and a filter reference spot (on which no particles accumulated) was sensed by photo diodes. Behind sample and reference spots there were Teflon ${ }^{\circledR}$ plates acting as a Lambertian diffusers, causing the light reaching the detectors to be diffuse. The photometer also measures the light backscattered from the soot spot on the filter surface at $40^{\circ}$ which enabled correction for scattering (Fig. 2).

The filter transmittance $(\tau)$ is the inverse of the extinction (ext) and is calculated as:

$\tau=\frac{1}{\text { ext }}=\frac{I_{\text {trans }}}{I_{\text {in }}}$,

where $I_{\text {in }}$ is the intensity of the incoming light and $I_{\text {trans }}$ of the transmitted light.

The difference in intensity of transmitted light between exposed and unexposed filter surface enables the calculation of the optical density (Od) for any filter-based method:

$\mathrm{Od}=\ln \left[\frac{I_{\text {unexpos }}}{I_{\text {expos }}}\right]$.

Here $I_{\text {unexpos }}$ is the light intensity transmitted through the unexposed filter and $I_{\text {expos }}$ through the exposed filter. Two photodiodes were used to measure $I_{\text {unexpos }}$ and $I_{\text {expos }}$ (Fig. 2). The light absorption coefficient due to particulate matter $\left(\sigma_{\text {ap }}^{\prime}\right)$ is defined as $O d$ per meter air column and is calculated by multiplying the spot area and dividing by the volume of air sampled:

$\sigma_{\text {ap }}^{\prime}=\frac{A}{V} \ln \left[\frac{I_{\text {unexpos }}}{I_{\text {expos }}}\right]$.

$A$ is the sample spot area on the PCMB filter $\left(0.5 \mathrm{~cm}^{2}\right.$ or $8 \mathrm{~mm}$ in diameter) and $V$ the volume of air passing through the filter during a given period of time. A second sensor measured the back-scattered light from the soot spot, $I_{40 \text {; expos, at }}$ $40^{\circ}$ relative to the incoming light in front of the filter, which enabled a correction for light scattering (Fig. 2). To perform the correction for light scattering, the back-scattered light from the unexposed filter surface ( $I_{40}$; unexpos $)$ is also needed. Therefore blank filters were measured before and after the exposed filters, and an average value of $I_{40}$; unexpos could be derived. A scattering density $\left(\mathrm{Sd}_{40}\right)$ for each interval was calculated according to:

$\mathrm{Sd}_{40}=\ln \left[\frac{I_{40 ; \text { unexpos }}}{I_{40 ; \text { expos }}}\right]$ 


\section{Light source}

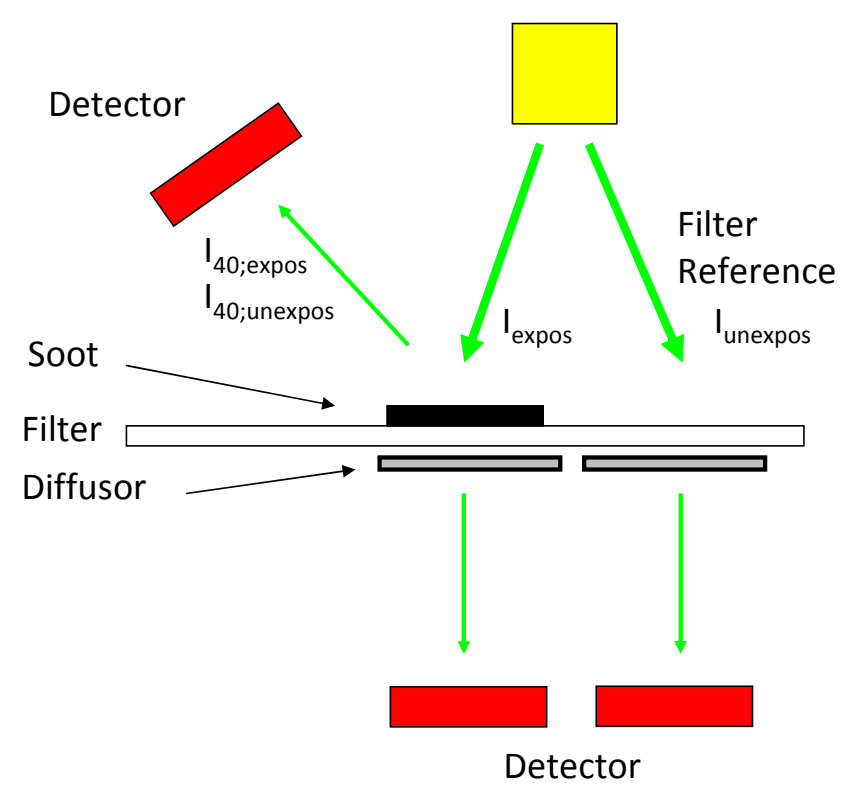

Fig. 2. The principle of the photometer instrument.

$\mathrm{Sd}_{40}$ is a measure of the change in intensity of the scattered light due to particles accumulated on the filter surface. By also taking the sampled air volume $(V)$ and the sample spot area $(A)$ into account, a scattering coefficient $\left(\sigma_{\mathrm{sp} ; 40}\right)$ for the back scattered light at $40^{\circ}$ was calculated,

$\sigma_{\mathrm{sp} ; 40}=\frac{A}{V} \ln \left[\frac{I_{40 ; \text { unexpos }}}{I_{40 ; \text { expos }}}\right]$.

Over a range of BC loadings on the PCMB filter the standard deviation $(1 \sigma)$ of the photometer instrument was established to be 0.0004 in units of Od and in units of $\sigma_{\mathrm{ap}}^{\prime}$ $0.0014 \mathrm{Mm}^{-1}$ (in relative measures better than 7, 0.03 and $0.009 \%$ for $\sigma_{\text {ap }}^{\prime}>0.02,5$ and $15 \mathrm{Mm}^{-1}$, respectively). The determined detection limit $(3 \sigma)$ was $0.0042 \mathrm{Mm}^{-1}$. By using a MAC value of $10 \mathrm{~m}^{2} \mathrm{~g}^{-1}$ (further discussed in Sect. 2.5) the obtained $\mathrm{BC}$ mass concentrations were $0.14 \mathrm{ngCm}^{-3}$ (in relative measures better than $7,0.03$ and $0.009 \%$ for concentrations $>2,500$ and $1500 \mathrm{ngCm}^{-3}$, respectively) and the resulting detection limit $(3 \sigma) 0.42 \mathrm{ngCm}^{-3}$.

Blank filters were analysed in the photometer and the instrument signal deviation was calculated. The filters were rotated stepwise in the photometer to investigate the internal variation of the filter surface. Through the rotation the position on the filter surface for the filter reference measurement were changed $90^{\circ}$, and four different part of the filter surface were compared. The relative standard deviation for the internal variability of the filter surface was $3.4 \%$. This value includes the standard deviation caused but the photometer itself. The filter to filter deviation were also calculated, but was found to add no additional variability on top on the internal filter variability.

When the variability of the blankfilters and the optical determination were combined with the variability of the flow measurement they all add up to an overall coefficient of variation for the sample collection and determination of $7 \%$.

\subsection{Correction of light absorption measurements}

\subsubsection{Optical correction}

The measured light absorption from the photometer instrument had to be corrected for light scattering by the nonabsorbing matter and for filter effects that both would influence the signal measured by the detector of the transmitted light through the PCMB filter. As mentioned in the introduction the filter effect depends on whether or not the particles are collected on the filter surface or embedded in the filter texture or both. This affects the length of the light path through the filter, which can lead to multiple absorption or scattering. The length of the light path is also affected by which angle the light is scattered (phase function). In conditions with high ambient particle concentrations in combination with too long sampling periods the determined BC levels constitute likely an underestimate, due to overloading of the filter samples. This is referred to as the filter shadowing effect in that aerosol particles are shadowed by other aerosol particles in the sample, and then not detected by the instrument. The shadowing effect can be reduced by adjusting the length of the sampling periods.

For the photometer using PCMB filters the optical filter correction due to filter effects and scattering is given by:

$\sigma_{\text {ap; optic-corr }}=\sigma_{\text {ap }}^{\prime} \times\left(\tau \times k_{1}+k_{2}\right)+\sigma_{\text {sp; } 40} \times k_{3}$.

Here $\sigma_{\text {ap; optic-corr }}$ is the corrected light absorption coefficient and $\sigma_{\mathrm{ap}}^{\prime}$ the uncorrected absorption coefficient from the photometer. $\tau$ is the transmittance of the filter sample and together with $k_{1}(0.0628)$ and $k_{2}(0.326)$ forms the optical correction for filter effects. $\sigma_{\mathrm{sp} ; 40}$ is the measured backscattered light at $40^{\circ}$ and multiplied with $k_{3}(0.00822)$ constitutes the optical correction for scattering, that is a calculated measure of the dependence of aerosol light scattering on the nonabsorbing chemical composition. $k_{1}, k_{2}$ and $k_{3}$ are empirical constants combining the former effect with errors related to filter effects. These constants were acquired by comparing the MISU photometer and a MAAP (Petzold et al., 2005). This was performed at an intercomparison workshop hosted by the Leibniz Institute for Tropospheric Research, Leipzig, Germany (Müller et al., 2011). The inlets of the two instruments were connected to a mixing chamber where synthetic BC (Printex 75, Evonik Degussa GmbH) and ammonium sulfate particles were continuously mixed. The single scattering albedo of the mixed particles during the comparison varied between 0.98 and 0.75 . After sampling different combinations of $k_{1}, k_{2}$ and $k_{3}$ were derived, using the solver function 
Table 1. Mass Absorption Cross-section values reported in the literature.

\begin{tabular}{|c|c|c|c|c|c|}
\hline Study & Method & Location & Period & MAC m $\mathrm{m}^{-1}$ & Remark* \\
\hline Mayol-Bracero et al. (2002) & PSAP at $\lambda=550 \mathrm{~nm}$ & INDOEX campaign & March 1999 & $5.6 \pm 0.8$ & $<4.0 \mu \mathrm{g} \mathrm{m}^{-3}$ \\
\hline Mayol-Bracero et al. (2002) & PSAP at $\lambda=550 \mathrm{~nm}$ & INDOEX campaign & February 1999 & $10.8 \pm 1.6$ & $<4.0 \mu \mathrm{g} \mathrm{m}^{-3}$ \\
\hline Kondo et al. (2009) & PSAP at $\lambda=565 \mathrm{~nm}$ & 6 sites in east Asia & 2004-2007 & $10.5 \pm 0.7$ & \\
\hline Adams et al. (1990) & $\begin{array}{l}\text { Photoacoustic spectroscopy } \\
\text { at } \lambda=514 \mathrm{~nm}\end{array}$ & Los Angeles & Summer 1987 & $10 \pm 0.5$ & \\
\hline
\end{tabular}

* BC mass concentration in air.

of Microsoft Excel®. The combination of the three $k$ values

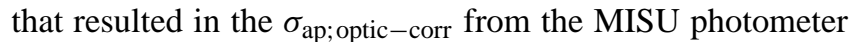
using Eq. 7 with least deviation from the $\sigma_{\text {ap }}$ of the MAAP instrument was chosen. The deviation for the combination chosen was $9.4 \%$. This means that with the selected optical correction algorithm $9 \%$ of the values could not be explained.

\subsubsection{Chemical correction}

By subsequent chemical quantification of each individual PCMB filter sample a direct estimate of the scattering effect of non-absorbing inorganic particles was provided. This was carried out for samples collected during two periods characterized with either continental (Arabian Sea) or remote marine (South Indian Ocean) influenced air (defined in Sect. 3.1).

The scattering of light by the analyzed inorganic mass fraction deposit on each filter sample collected $\left(\sigma_{\mathrm{sp} \text {;ionmass }}\right)$ was estimated through multiplying the total detected ionic mass ( $\left.C_{\text {ionmass }}\right)$ by the mass scattering efficiency (MSE) specific to the source area of the selected periods (Eq. 8).

$\sigma_{\mathrm{sp} ; \text { ionmass }}=C_{\text {ionmass }} \times \mathrm{MSE}$

A value of $3.8 \mathrm{~m}^{2} \mathrm{~g}^{-1}$ was used for MSE as reported by Clarke et al. (2002). A linear regression analysis was then performed on the measured $\sigma_{\text {ap }}^{\prime}$ and the calculated $\sigma_{\mathrm{sp} \text {; ionmass }}$. From the obtained relationship in Eq. (9)

$\sigma_{\mathrm{ap}}^{\prime}=k \times \sigma_{\mathrm{sp} ; \text { ionmass }}+c$,

the slope $k$ multiplied with $\sigma_{\mathrm{sp} \text {;ionmass }}$ is an estimate of the fraction of the measured light absorption $\sigma_{\text {ap }}^{\prime}$ resulting from the scattering by non-absorbing inorganic matter. The value determined for the linear regression correction parameter $k$ was $0.247(R=0.91)$ for the Arabian Sea group and 0.081 ( $R=0.53$ ) for the South Indian Ocean group.

The intercept $c$ in Eq. (9) represents the "true" absorption together with added errors associated with the PCBM filter itself ("filter effects"). A constant $c=0.268$ was used in the corrections for all samples. It was estimated from the samples collected in air with a minimum influence of continental combustion sources and was chosen to represent the least absorption from aerosol particles that could have interfered with the estimation of the filter effect itself.

The corrected light absorption coefficient $\sigma_{\text {ap;chem-corr }}$ was obtained applying Eq. (10) to each individual sample:

$\sigma_{\mathrm{ap} ; \mathrm{chem}-\mathrm{corr}}=\sigma_{\mathrm{ap}}^{\prime}-k \times \sigma_{\mathrm{sp} ; \text { ionmass }}-0.268$

\subsection{Chemical analyses of the Nuclepore ${ }^{\circledR}$ filters using IC}

To allow for subsequent chemical determinations all PCMB filters, ambient samples and blanks were carefully handled in a glove box (free from particles, sulfur dioxide and ammonia) both prior to and after sampling. At the time of the chemical analyses, still in the glove-box, the filters were extracted (in centrifuge tubes) with $5 \mathrm{~cm}^{3}$ deionized water (18 $\mathrm{M} \Omega \mathrm{cm})$. For sufficient extraction the filter extracts were finally placed in an ultra sonic bath for $60 \mathrm{~min}$. The extracts were then analyzed for major cations, anions and weak anions by chemically suppressed ion chromatography (IC, Dionex ICS-2000). The anions were analyzed with Dionex AG11/AS11 columns and the cations with CG16/CS16. The injection volume was $50 \mu \mathrm{dm}^{3}$. Quality checks of the analyses were performed with both internal and external reference samples (BMC). The analytical detection limits obtained for the various ions, defined as twice the level of peak-to-peak instrument noise, were $0.20,0.05,0.10,0.01,0.01$ and 0.25 , $0.02,0.01$, and $0.001 \mu \mathrm{eqdm}{ }^{-3}$, for sodium $\left(\mathrm{Na}^{+}\right)$, ammonium $\left(\mathrm{NH}_{4}^{+}\right)$, potassium $\left(\mathrm{K}^{+}\right)$, magnesium $\left(\mathrm{Mg}^{2+}\right)$, calcium $\left(\mathrm{Ca}^{2+}\right)$, and chloride $\left(\mathrm{Cl}^{-}\right)$, nitrate $\left(\mathrm{NO}_{3}^{-}\right)$, sulfate $\left(\mathrm{SO}_{4}^{2-}\right)$, and methane sulfonate (MSA), respectively. The overall analytical accuracy was better than $5 \%$ and $7 \%$ for the anions and cations. The average particulate $\mathrm{Na}^{+}, \mathrm{NH}_{4}^{+}, \mathrm{K}^{+}, \mathrm{Mg}^{2+}$, $\mathrm{Ca}^{2+}, \mathrm{Cl}^{-}, \mathrm{NO}_{3}^{-}$and $\mathrm{SO}_{4}^{2-}$ blank concentrations were $<5 \%$, $<3 \%,<1 \%,<0.2 \%,<0.3 \%,<6 \%,<32 \%$ and $<0.2 \%$ of the sample, respectively. Non-sea-salt (nss)-SO $\mathrm{SO}_{4}^{2-}$ - concentrations were calculated by using sodium concentrations and seawater composition taken from Stumm and Morgan (1981). The sea-salt contribution was on average less than $0.5 \%$ ("Arabian Sea"); $4 \%$ ("South Indian Ocean") of the total submicrometer $\mathrm{SO}_{4}^{2-}$-concentrations. 
Table 2. Samples collected at MCOH during the two data selections. Data shown are uncorrected absorption coefficient $\left(\sigma_{\mathrm{ap}}\right)$ values and BC mass concentrations, data corrected with the optical protocol and data corrected with the chemical protocol. Also shown are scattering coefficient $\left(\sigma_{\mathrm{sp}}\right)$ values calculated using measured ion mass and a mass scattering efficiency of $3.8 \mathrm{~m}^{2} \mathrm{~g}^{-1}$. Units for $\left(\sigma_{\mathrm{ap}}\right)$ and $\left(\sigma_{\mathrm{sp}}\right)$ are in $\mathrm{Mm}^{-1}$ and for $\mathrm{BC}$ mass concentration in $\mu \mathrm{gm}^{-3}$. BC mass concentrations were derived using a mass absorption cross-section of $10 \pm 1 \mathrm{~m}^{2} \mathrm{~g}^{-1}$.

\begin{tabular}{|c|c|c|c|c|c|c|c|}
\hline & $\begin{array}{r}\text { Un- } \\
\text { corrected } \\
\sigma_{\mathrm{ap}}\end{array}$ & $\begin{array}{r}\text { Optical } \\
\text { corrected } \\
\sigma_{\mathrm{ap}}\end{array}$ & $\begin{array}{r}\text { Chemical } \\
\text { corrected } \\
\sigma_{\mathrm{ap}}\end{array}$ & $\begin{array}{r}\sigma_{\mathrm{sp}} \\
\text { from total } \\
\text { ion mass }\end{array}$ & $\begin{array}{r}\mathrm{BC} \\
\text { uncorrected }\end{array}$ & $\begin{array}{r}\mathrm{BC} \\
\text { optical } \\
\text { corrected }\end{array}$ & $\begin{array}{r}\mathrm{BC} \\
\text { chemical } \\
\text { corrected }\end{array}$ \\
\hline $\begin{array}{l}\text { Arabian Sea } \\
\text { No. of samples: } 40\end{array}$ & \multicolumn{7}{|c|}{18 March 2007 to 3 May 2007} \\
\hline Average & 12 & 4.6 & 3.5 & 36 & 1.2 & 0.46 & 0.35 \\
\hline 50th percentile (median) & 11 & 4.2 & 3.5 & 33 & 1.1 & 0.42 & 0.35 \\
\hline 75th percentile & 15 & 5.6 & 4.0 & 47 & 1.5 & 0.56 & 0.40 \\
\hline 25 th percentile & 8.8 & 3.3 & 2.1 & 28 & 0.88 & 0.33 & 0.21 \\
\hline $\begin{array}{l}\text { South Indian Ocean } \\
\text { No. of samples: } 15\end{array}$ & \multicolumn{7}{|c|}{1 June 2007 to 23 September 2007} \\
\hline Average & 1.5 & 0.58 & 0.17 & 6.8 & 0.15 & 0.058 & 0.017 \\
\hline 50th percentile (median) & 1.0 & 0.38 & 0.026 & 6.8 & 0.10 & 0.038 & 0.0026 \\
\hline 75th percentile & 2.3 & 0.88 & 0.36 & 7.8 & 0.23 & 0.088 & 0.036 \\
\hline 25 th percentile & 0.67 & 0.26 & -0.20 & 4.4 & 0.067 & 0.026 & -0.020 \\
\hline
\end{tabular}

\subsection{Mass absorption cross-section}

To establish the mass concentration of BC from the estimated light absorption, a mass absorption cross-section (MAC) was used. Notably, this factor is unique for each composition of aerosol particles and wavelength, thus adding further uncertainties to the estimate of atmospheric BC abundances. Table 1 shows published data on established MAC values and the method and wavelength in use. An uncertainty of $\pm 10 \%$ seems to be appropriate according to published literature. Preferably a specific MAC value should be used for each region and season of sample collection. Bond and Bergstrom (2006) recommend a MAC value of $7.5 \pm 1.2 \mathrm{~m}^{2} \mathrm{~g}^{-1}$ for airborne uncoated $\mathrm{BC}$ particles, but due to the ageing processes of BC during its atmospheric lifetime, this value can only be expected to be relevant for measurements close to the source.

Therefore a value of $\mathrm{MAC}=10 \pm 1.0 \mathrm{~m}^{2} \mathrm{~g}^{-1}$ was applied to estimate the concentration of ambient aerosol particles aged in the atmosphere (Adams et al., 1990; Mayol-Bracero et al., 2002; Kondo et al., 2009). This is also the MAC value recommended by the commercial PSAP manufacturer.

\subsection{Trajectory analysis}

To evaluate possible source regions for air sampled at surface level at $\mathrm{MCOH}$, modelled trajectories were used. These were calculated backwards for 10 days with the Hysplit model (version 4.8) developed at NOAA (Draxler and Rolph, 2003). The choice of 10 days was made according to the expected lifetime of the sampled aerosol particles. The arrival height for the trajectories was set to $50 \mathrm{~m}$. When using trajectory data, one must take into account the number of uncertainties in the trajectory models, as discussed by (Stohl, 1998) among others.

\section{Results and discussion}

\subsection{Data selection}

During the dry winter season (November-April), the mean wind direction at $\mathrm{MCOH}$ is northeasterly associated with air influenced by anthropogenic activities from the Indian subcontinent, such as combustion. During the wet summer monsoon (June-September), the mean wind direction at $\mathrm{MCOH}$ is southwesterly associated with marine air from the southern hemisphere Indian Ocean. The air masses accumulate moisture over the Indian Ocean and deposit large amounts of precipitation over India and the surrounding regions. Between the two seasons a transition occurs with variable wind directions lasting for about 4 to 5 weeks (Corrigan et al., 2006).

The Indian subcontinent is a major source region of anthropogenic emissions from biomass burning and fossil fuel combustion (Reddy et al., 2004; Nair et al., 2005), with the former dominating the $\mathrm{BC}$ composition according to $\mathrm{C}$ 14 analysis performed at samples from $\mathrm{MCOH}$ (Gustafsson et al., 2009). Mineral dust from the Middle East/Arabian peninsula is transported southwards over the Arabian Sea mixed with anthropogenic influenced aerosol particles from the Indian subcontinent and sea salt before reaching the MCOH (Nair et al., 2005). The South Indian Ocean region 


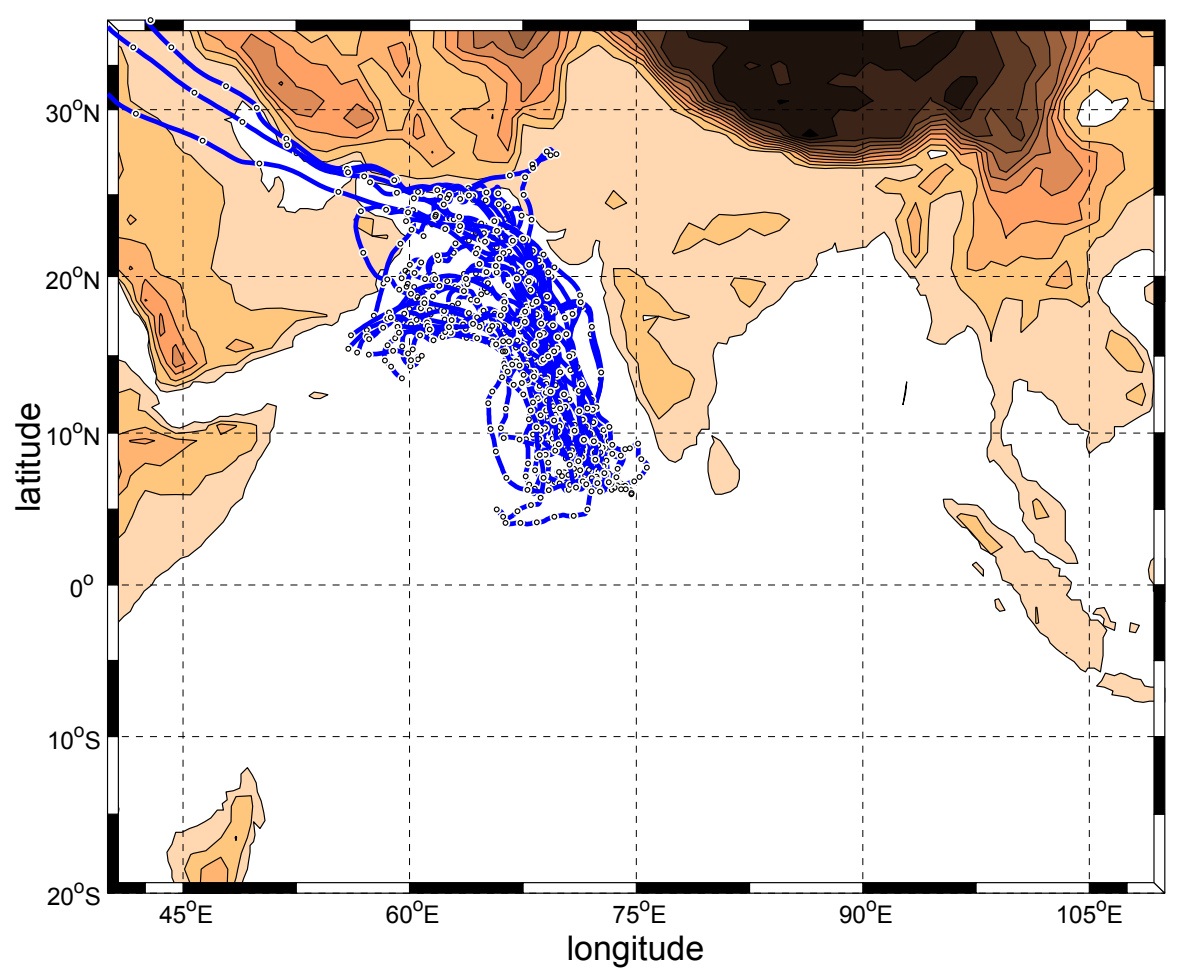

Fig. 3. 10 days backward trajectory cluster with the arriving hight of $50 \mathrm{~m}$ for the data selection "Arabian Sea".

is mainly a contributor of biogenic derived sulfur containing particles and sea salts (Norman et al., 2003).

Considering both the source regions and the meteorological situation leads to the election of two time periods being representative for continental influenced air with relatively high light absorption of $\mathrm{BC}\left(4 \mathrm{Mm}^{-1}\right)$ and for air with a minimal influence from combustion sources $\left(0.4 \mathrm{Mm}^{-1}\right)$. Section 3.2 and Table 2 give further details of the estimates. The first period (17 March to 3 May 2007) occurred within the winter season and was characterized by trajectories starting in the northern part of the Arabian Sea, then moving south along the west coast of the Indian subcontinent to finally end at $\mathrm{MCOH}$ (Fig. 3). During the second period within the summer monsoon (1 June 2007 to 24 September 2007) the 10day trajectories originated from the southeast with the remote marine Southern Indian Ocean as source region (Fig. 4).

The total analyzed inorganic mass composition showed that the air arriving from the Arabian Sea $\left(9.1 \mu \mathrm{gm}^{-3}\right.$, median value) had a 5-fold higher mass, compared to South Indian Ocean $\left(1.70 \mu \mathrm{gm}^{-3}\right.$, median value). $\mathrm{SO}_{4}^{2-}$, followed by $\mathrm{NH}_{4}^{+}, \mathrm{Na}^{+}$and $\mathrm{BC}$ dominated the samples with source regions over the Arabian Sea and the Indian subcontinent (Table 3, Fig. 5). The strong contribution from nss- $\mathrm{SO}_{4}^{2-}, \mathrm{K}^{+}$ and $\mathrm{NH}_{4}^{+}$, being indicators of combustion and agriculture, is in alignment with the closeness to the Indian subcontinent. An additional feature was the elevated concentration of $\mathrm{Ca}^{2+}$ measured, which indicated transport of crustal material from the large desert areas in the Middle East. Both recent satellite retrievals (Kaufman et al., 2001) and data from the AERONET network of ground-based radiometers (Dubovik et al., 2002) from the Middle East/Arabian peninsula show low light absorption by dust in the visible to near-infrared wavelengths. Therefore it is assumed that in this case the main influence of crustal material on optical measurements of BC is through light scattering and thus being accounted for in the chemical correction protocol applied in this study.

When the air originated from the South Indian Ocean $\mathrm{SO}_{4}^{2-}$ still dominated the inorganic mass composition, with the two sea salt components $\mathrm{Na}^{+}$and $\mathrm{Cl}^{-}$being the second most common. The strong contribution from nss- $\mathrm{SO}_{4}^{2-}$ was in agreement with previous findings where virtually all nss$\mathrm{SO}_{4}^{2-}$ was likely to have been derived from the marine biogenic source of dimethyl sulfide (Norman et al., 2003). The strong contribution from $\mathrm{NaCl}$, as expected in marine influenced air, was also in agreement with Norman et al. (2003).

\subsection{Implementation of the correction methods on PCMB filter-based optical measurements of BC}

To reduce systematic errors dominated by the optical effects of non-absorbing particles when using filter-based determinations of $\mathrm{BC}$, the two independent methods of corrections 




Fig. 4. 10 days backward trajectory cluster with the arriving hight of 50 meter for the data selection "South Indian Ocean".

described in Sect. 2.3 (the optical by use of the $\sigma_{\mathrm{sp}}$ instrument and the chemical based on the linear regression of the uncorrected $\sigma_{\text {ap }}^{\prime}$ and $\sigma_{\mathrm{sp} \text {;ionmass }}$ ) were each applied to the uncorrected $\sigma_{\text {ap }}^{\prime}$ of the samples collected at the $\mathrm{MCOH}$. Based on a trajectory analyses and verified by the chemical quantifications (Fig. 5, Tables 2 and 3) the samples were representative for episodes with either continental influenced air from the Indian/Arabian subcontinents or pristine air from the Southern Indian Ocean.

Through the optical correction, the empirically derived values of $k_{1}, k_{2}$ and $k_{3}$ in Eq. (7), were applied to both data selections. The benefits in using the chemical quantification of the non-absorbing matter collected on the PCMB filters was that a $C_{\text {ionmass }}$ could be quantified for each individual filter sample combined into the two groups separately as recommended by Bond et al. (1999) (Sect. 2.3.2).

The optical correction resulted in a median $\sigma_{\text {ap }}$ for the "Arabian Sea" of $4.2 \pm 0.04(90 \%$ confidence interval) $\mathrm{Mm}^{-1}$ (Table 2). The "Arabian Sea" median $\sigma_{\text {ap }}$ derived from the chemical correction $\left(3.5 \pm 0.04 \mathrm{Mm}^{-1}\right)$ was less than $20 \%$ lower compared to the optical correction. For the "South Indian Ocean" group corresponding values, $0.38 \pm 0.02$ and $0.02 \pm 0.02 \mathrm{Mm}^{-1}$, were significantly different at a $90 \%$ confidence interval, with the chemical corrections not statistically separated from zero. The optical correction lowered the $\sigma_{\text {ap }}$ with $61 \%$ for the samples collected within the "Arabian Sea" group and with $63 \%$ for the "South
Indian Ocean" group. The chemical correction lowered the $\sigma_{\text {ap }}$ with $69 \%$ and as much as $97 \%$ for the "Arabian Sea" and "South Indian Ocean" data selections, respectively (Table 4 and Fig. 6). The resulting relativly strong chemical correction for the "South Indian Ocean" data suggests the optical correction to be less sensitive to the amount of non-absorbing particle matter deposit on the filter.

Table 5 gives a comparison of the $\mathrm{BC}$ mass concentrations derived in this study with two other studies performed within the Indian Ocean region. Reported values for the winter season varied between 1 to $5 \mathrm{Mm}^{-1}$ (Quinn et al., 2002) and 7.1 to $19 \mathrm{Mm}^{-1}$ (Corrigan et al., 2006). The former levels were in the same range as the values reported in this study with the latter range being 2 to 5 times higher. During the summer monsoon the reported conditions in this study were dissimilar in comparison with the elevated data of Corrigan et al. (2006) in being up to two orders of magnitude in difference.

Quinn et al. (2002) measured the light absorption coefficient with a PSAP instrument using the correction protocol of Bond et al. (1999). It takes into account the effect of scattering in general, but uses pre set values for the correction parameters and by that does not account for variations in the scattering by the non-absorbing aerosol material. This was motivated by the $(2 \%)$ increase in light absorption due to scattering.

Corrigan et al. (2006) used an aethalometer to measure the light absorption coefficient and implemented a correction 

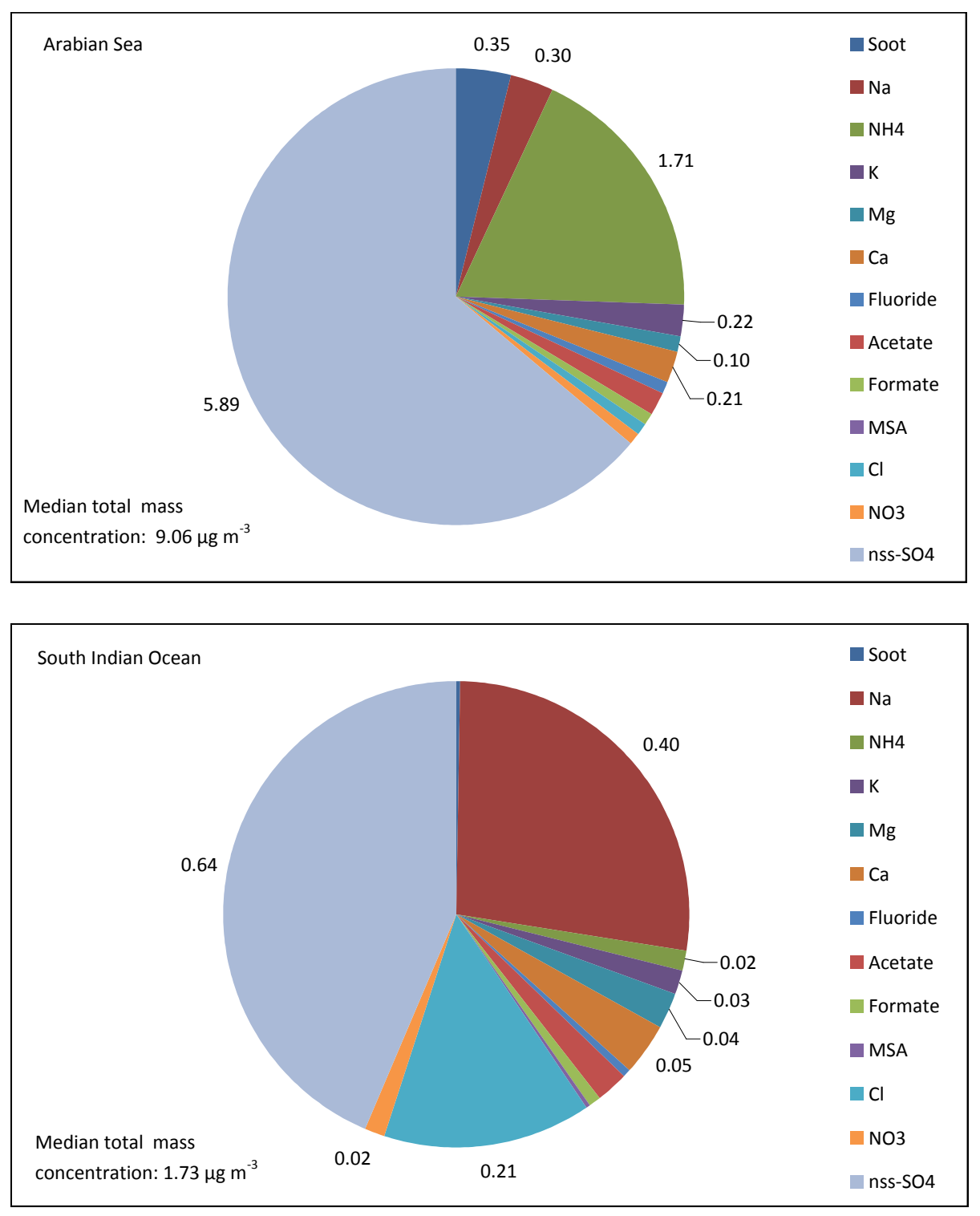

Fig. 5. Median aerosol composition and the sum of median ion mass and median BC mass (derived using the chemical correction) for the two data selections. Units are given in $\mu \mathrm{gm}^{-3}$. BC mass concentrations were derived using a mass absorption cross-section of $10 \pm 1 \mathrm{~m}^{2} \mathrm{~g}^{-1}$.

protocol developed by Arnott et al. (2005). The protocol was optimized for continental conditions and applied an empirically derived routine based on laboratory and field absorption measurements performed together with a photoacoustic photometer to acquire corrected light absorption coefficients. The parameters in the Corrigan method were fixed to certain pre set values and not adjusted continuously to take into account variations in the optical properties of the aerosol particles collected. The correction method developed by Arnott et al. (2005) were not valid for clean air conditions at the $\mathrm{MCOH}$ as negative $\sigma_{\mathrm{ap}}$ were retrieved. To solve this problem the scattering correction in Arnott et al. (2005) was tuned to only generate positive $\sigma_{\text {ap }}$ values. After this adjustment the results of Corrigan et al. (2006) showed a contribution of scattering to the absorption measurements similar to the low $2 \%$ reported by Bond et al. (1999).

It was shown above that the applied methods of correcting for optical effects of non-absorbing particles gave a different weighting to the errors involved in optical filter-based determinations of BC. The largest errors were attributed to the most simplified protocol applied, in which not only the correction of the light scattering was assumed independent on changes in aerosol composition and amount but also tuned to generate positive $\mathrm{BC}$ levels. This raises the necessity for chemical correction protocols on optical filter-based determinations of $\mathrm{BC}$.

However, concern could be raised when avoiding to address the mixing state of the particulate matter deposited 
Table 3. Samples collected at $\mathrm{MCOH}$ during the two data selections. Data shown are ion mass concentrations and the sum of ion mass and $\mathrm{BC}$ mass derived using the chemical correction protocol. Units are $\mu \mathrm{gm}^{-3}$. BC mass concentrations were derived using a mass absorption cross-section of $10 \pm 1 \mathrm{~m}^{2} \mathrm{~g}^{-1}$.

\begin{tabular}{|c|c|c|c|c|c|c|c|}
\hline & $\mathrm{SO}_{4}^{2-}$ & nss-SO ${ }_{4}^{2-}$ & $\mathrm{NH}_{4}^{+}$ & $\mathrm{Na}^{+}$ & $\mathrm{K}^{+}$ & $\mathrm{Ca}^{2+}$ & $\begin{array}{r}\text { Total ion } \\
\text { and } \mathrm{BC} \text { mass }\end{array}$ \\
\hline Arabian Sea & \multirow{2}{*}{\multicolumn{7}{|c|}{18 March 2007 to 3 May 2007}} \\
\hline No. of samples: 40 & & & & & & & \\
\hline Average & 6.5 & 6.5 & 1.7 & 0.42 & 0.26 & 0.23 & 15 \\
\hline 50th percentile (median) & 5.9 & 5.9 & 1.7 & 0.30 & 0.22 & 0.21 & 9.1 \\
\hline 75th percentile & 8.5 & 8.4 & 2.1 & 0.49 & 0.38 & 0.30 & 13 \\
\hline 25th percentile & 4.8 & 4.8 & 1.2 & 0.23 & 0.16 & 0.11 & 7.2 \\
\hline \multicolumn{8}{|l|}{ South Indian Ocean } \\
\hline No. of samples: 15 & \multicolumn{7}{|c|}{1 June 2007 to 23 September 2007} \\
\hline Average & 0.84 & 0.81 & 0.061 & 0.43 & 0.040 & 0.055 & 2.1 \\
\hline 50th percentile (median) & 0.67 & 0.64 & 0.018 & 0.40 & 0.028 & 0.051 & 1.7 \\
\hline 75th percentile & 0.98 & 0.96 & 0.063 & 0.49 & 0.041 & 0.056 & 2.0 \\
\hline 25 th percentile & 0.56 & 0.54 & 0.016 & 0.27 & 0.020 & 0.043 & 1.2 \\
\hline
\end{tabular}

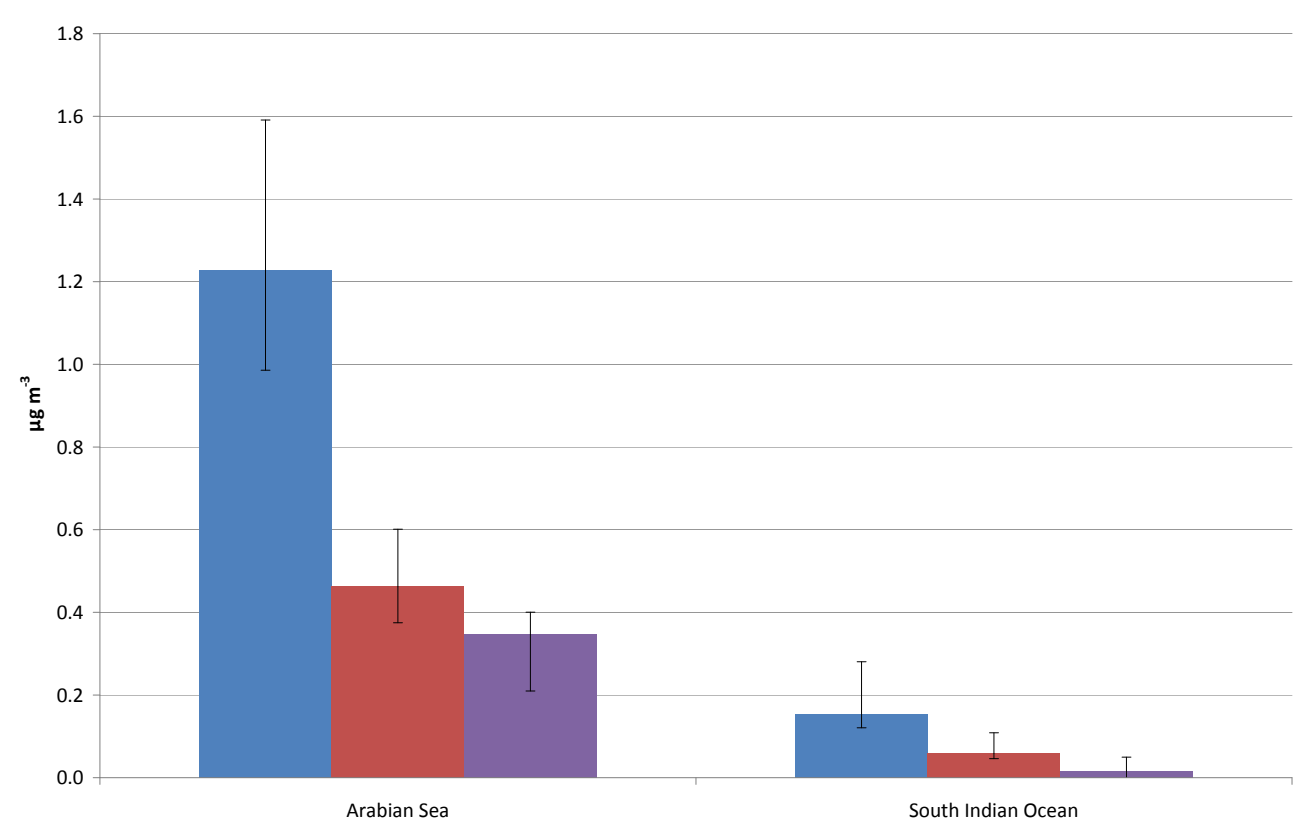

Fig. 6. Uncorrected absorption coefficient values (blue), compared with two different methods of correction (optical correction $=$ dark red and chemical correction $=$ purple) implemented on the uncorrected values for the two data selections. Bars indicate 75 and 25 percentiles. The coefficient of variation of the method is included in the spread of the sample population indicated by the bars. BC mass concentrations were derived using a mass absorption cross-section od $10 \pm 1 \mathrm{~m}^{2} \mathrm{~g}^{-1}$.

on the filter matrix: if a particle deposited on the filter has a light-scattering core coated with light-absorbing material, the optical instrument will "see" that particle as an absorbing material. However, the bulk chemical analyses of the same filter will reveal an inorganic fraction, which would be mainly composed of scattering material, that is, the particle might contribute to the light scattering when in fact the particle is seen as an absorber by the optical instrument.
Coz and Leck (2011) quantified the morphological characteristics and state of mixture of soot aggregates in air at the $\mathrm{MCOH}$ station during the same winter collection period as of this study. They showed that 11-29\% of the aggregates sampled at $\mathrm{MCOH}$ were coated with an organic layer and $17-25 \%$ with an inorganic layer, depending on the source region. The remaining being closed "soot (BC)"-aggregates only. To be concluded is that the concern addressed, did not 
Table 4. Samples collected at MCOH during the two data selections. The average of median values is calculated using the median values from the optical and chemical corrected BC concentrations. BC average values are in $\mu \mathrm{gm}^{-3}$, all other values are dimensionless ratios. $\mathrm{BC}$ mass concentrations were derived using a mass absorption cross-section of $10 \pm 1 \mathrm{~m}^{2} \mathrm{~g}^{-1}$.

\begin{tabular}{lcccr}
\hline & $\begin{array}{r}\text { BC/ } \\
\text { Total } \\
\text { mass }\end{array}$ & $\begin{array}{r}\text { BC } \\
\text { Average of } \\
\text { median mass }\end{array}$ & $\begin{array}{r}\text { Optical } \\
\text { correction } \\
\text { effect }\end{array}$ & $\begin{array}{r}\text { Chemical } \\
\text { correction } \\
\text { effect }\end{array}$ \\
\hline $\begin{array}{l}\text { Arabian Sea } \\
\text { No. of samples: 40 }\end{array}$ & & 18 Mars 2007 to 3 May 2007 & \\
\hline Average & 0.026 & 0.40 & 0.62 & 0.72 \\
50th percentile (median) & 0.041 & 0.38 & 0.63 & 0.69 \\
\hline South Indian Ocean & & 1 June 2007 to 23 September 2007 & \\
No. of samples: 15 & 0.017 & 0.037 & 0.62 & 0.89 \\
\hline Average & 0.012 & 0.0020 & 0.61 & 0.97 \\
\hline 50th percentile (median) & 0.021 & 0.22 & 0.62 & 0.80 \\
\hline Averaged median values & 0.021 & & & \\
\hline
\end{tabular}

apply to samples collected in air at the $\mathrm{MOCH}$ site during the winter season.

One further concern that has to be address is if other scattering matter such as organic carbon, OC, will lead to corrections of the aerosol light absorbing coefficient that are even larger than those that were being derived with only the inorganics accounted for as in this study. In recent years a number of studies have suggested that the presence of OC codeposited on the filter-matrix could have a significant effect on aerosol light absorbing measurements (Schnaiter et al., 2006; Subramanian et al., 2007; Cappa et al., 2008; Lack et al., 2008). The most polluted case at MCOH could probably equal the "Urban-downwind" case in the classification. In one such case, the estimated enhancement factor of the light absorption was 1.27 (Lack et al., 2008).

This larger apparent absorption, called the lens effect, assumes that the OC is internally mixed with the "soot (BC)"aggregate, in being consistent with Coz and Leck (2011). The light beam (at $\lambda=528 \mathrm{~nm}$ ) will pass the transparent organic coating, which enables the beam to be focused on the absorbent "soot (BC)"-core. The absorbing core will intercept more of the incoming light with a reduction in the transmitted light as a result. Therefore, a larger apparent absorption will be detected.

Without information on the aerosol state of mixture Quinn et al. (2002) reported a mass fraction of $<15 \%$ for OC and up to $7 \%$ for $\mathrm{BC}$ in the outflow from the Indian subcontinent. Mayol-Bracero et al. (2002) found a mass fraction of $35 \%$ for OC and $14 \%$ for BC. So even if we allow for the lens effect by internally mixed OC, more than $65 \%$ of the non-absorbing mass is made up by non-absorbing constituents other than OC. In the light of these results, including the morphology study by Coz and Leck (2011), there is not a major contribution of OC to the non absorbing particulate matter to be accounted for in the chemical correction protocols. Never the less, empirical corrections including OC are still both desirable and required to reduce uncertainties in optical effects of non or low absorbing constituents. New instrumental development should thus include also determinations of OC mixing state and morphology co-deposited on the filter-matrix.

\section{Conclusions}

For global assessments of climate effects of soot global data are required, most importantly in regions where strong economic developments imply substantial increases in atmospheric concentrations, such as India, South-East Asia, and China. From the latter region the first reports on $\operatorname{soot}(\mathrm{BC})$ related climate forcings over the past decade emphasize the urgency of better atmospheric data. The presented method uses instrumentation of low cost of construction that can be implemented in the field under primitive conditions. This enables researchers with small economical means to perform monitoring at remote locations, especially in Asia where it is much needed.

By monitoring the change in transmitted light through a filter loaded with aerosol particles, estimates of the light absorption of $\mathrm{BC}$ are possible. We present a newly designed photometer instrument constructed to measure light transmission, at $528 \mathrm{~nm}$, and features an additional sensor recording the backscattered light at $40^{\circ}$ relative to the incoming light in front of the filter. The choice of PCMB filters instead of the otherwise so commonly used fiber glass filters was not only advantageous in avoiding high chemical blank values but also to reduce errors associated with length of the light path through the filter since the particles are deposit on the filter surface and not embedded in the filter texture. 
Table 5. Absorption coefficient values in air measured with optical techniques in the Indian Ocean region. BC mass concentrations were derived using a mass absorption cross-section of $10 \pm 1 \mathrm{~m}^{2} \mathrm{~g}^{-1}$.

\begin{tabular}{lrrrr}
\hline Study & $\begin{array}{r}\text { Summer monsoon } \\
\mathrm{Mm}^{-1}\end{array}$ & $\begin{array}{r}\text { Winter season } \\
\mathrm{Mm}^{-1}\end{array}$ & $\begin{array}{r}\text { Summer monsoon } \\
\mathrm{\mu gm}^{-3}\end{array}$ & $\begin{array}{r}\text { Winter season } \\
\mu \mathrm{gm}^{-3}\end{array}$ \\
\hline Engström and Leck (2009) & $0.02-0.38$ & $3.5-4.2$ & $0.002-0.038$ & $0.35-0.42$ \\
Corrigan et al. (2006) & $0.87 \pm 0.56$ & $11.7 \pm 4.6$ & $0.087 \pm 0.056$ & $1.17 \pm 0.46$ \\
Quinn et al. (2002) & $<\mathrm{LOD}(0.34)$ & $1.0-5.0$ & $<\mathrm{LOD}(0.034)$ & $0.1-0.5$ \\
\hline
\end{tabular}

In spite of several well-established approaches on filterbased optical measurements of BC the reported data suffer however from systematic errors that could lead to an overestimation of the recorded light absorption of $\mathrm{BC}$. The errors are dominated by the dependence of aerosol light scattering on the chemical composition of non-absorbing particles, such as inorganic salts and mineral dust, in the sample. In an attempt to reduce the systematic errors this study establishes protocols for correction of light scattering provided by the chemical quantification of the non-absorbing material collected on the filter and measured back-scattered light. The two protocols of corrections were applied to ambient aerosol samples collected at the $\mathrm{MCOH}$ during episodes with either continental influenced air from the Indian/Arabian subcontinents representative for the dry winter season or pristine air from the Southern Indian Ocean during the wet summer monsoon.

The optical correction lowered the determined light absorption of BC with $61 \%$ for the samples collected within the "Arabian Sea" group and with $63 \%$ for the "South Indian Ocean" group. Corresponding values for the chemical correction were $69 \%$ and $97 \%$. This result indicates that the optical correction is less sensitive to the amount of nonabsorbing particle matter deposit on the filter. In a comparison of this studys determined light absorption of BC with other studies in the area, in which the light scattering simplistically was assumed independent of changes in aerosol composition and amount, resulted in an overestimation of the $\sigma_{\text {ap }}$, by up to two orders of magnitude. Therefore, this study emphasis the need to reduce errors dominated by optical effects of non-absorbing particles in filter-based measurements of BC by applying protocols on the dependence of aerosol chemical composition.

Despite these BC-related uncertainties trends in atmospheric $\mathrm{BC}$ burdens due to the increased use of $\mathrm{BC}$ producing combustion sources have led to a rapidly increasing number of model simulations, which ascribe strong climate forcing to the black material in soot (Jacobson, 2000). In some of these studies the modelled positive forcing becomes comparable to those of carbon dioxide (Jacobson, 2002), from which the authors concluded that a reduction of $\mathrm{BC}$ emissions might be immediately more efficient and costeffective than concentrating abatement strategies on greenhouse gases. Thus the necessity for chemical correction protocols raised here, before even the sign on the radiative forcing by dark soot particles can be assessed, will certainly be controversial. What is required is not automatic rejection but careful future consideration.

Acknowledgements. We thank the staff at Maldives Climate Observatory Hanimaadhoo for collecting the samples and the staff at the Department of Meteorologys laboratory for the help in analyzing them. Jost Heintzenberg and Thomas Müller are appreciated for fruitful scientific discussions. Special thanks go to Lennart Granat and Leif Bäcklin who designed and constructed the photometer instrument and to Agneta Öhrström for providing the IC analyses. The Swedish Natural Science Research Council and Swedish International Development Cooperation Agency (SIDA) funded the research. Additional financial support was received from Helge Ax:son Johnsons foundation, and a EU Marie Curie scholarship to E. Engström.

Edited by: D. Toohey

\section{References}

Adams, K. M., Davis, L. I., and Japar, S. M.: Measurement of atmospheric elemental carbon: real-time data for Los Angeles during summer 1987, Atmos. Environ., 24A, 597-604, 1990.

Andreae, M. O. and Gelencsér, A.: Black carbon or brown carbon?, The nature of light-absorbing carbonaceous aerosols, Atmos. Chem. Phys., 6, 3131-3148, doi:10.5194/acp-6-3131-2006, 2006.

Arnott, W. P., Hamasha, K., Moosmuller, H., Sheridan, P. J., and Ogren, J. A.: Towards aerosol light-absorption measurements with a 7-wavelength Aethalometer: Evaluation with a photoacoustic instrument and 3-wavelength nephelometer, Aerosol. Sci. Tech., 39, 17-29, 2005.

Bond, T. and Bergstrom, R.: Light absorption by carbonaceous particles: An investigative review, Aerosol. Sci. Tech., 40, 27-67, 2006.

Bond, T., Theodore, L., Anderson, T., and Campbell, D.: Calibration and intercomparison of filter-based measurements of visible light absorption by aerosols, Aerosol. Sci. Tech., 30, 582-600, 1999.

Cappa, C. D., Lack, D. A., Burkholder, J. B., and Ravishankara, A. R.: Bias in Filter-Based Aerosol Light Absorption Measurements Due to Organic Aerosol Loading: Evidence from Laboratory Measurements, Aerosol. Sci. Tech., 42, 1022-1032, 2008.

Clarke, A. D., Howell, S., Quinn, P., Bates, T., Ogren, J., Andrews, E., Jefferson, A., Massling, A., Mayol-Bracero, O., Maring, H., Savoie, D., and Cass, G.: INDOEX aerosol: A comparison and 
summary of chemical, microphysical, and optical properties observed from land, ship, and aircraft, J. Geophys. Res.-Atmos., 107, 8033, doi:10.1029/2001JD000572, 2002.

Clarke, A. D., Noone, K. J., Heintzenberg, J., Warren, S. G., and Covert, D. S.: Aerosol light absorption measurement techniques analysis and intercomparisons., Atmos. Environ., 21, 1455-1465, 1987.

Corrigan, C. E., Ramanathan, V., and Schauer, J. J.: Impact of monsoon transitions on the physical and optical properties of aerosols, J. Geophys. Res.-Atmos., 111, D18208, doi:10.1029/2005JD006370, 2006.

Coz, E. and Leck, C.: Morphology and state of mixture of atmospheric soot aggregates during the winter season over Southern Asia - a quantitative approach, Tellus B, 63, 107-116, 2011.

Draxler, R. and Rolph, G.: HYSPLIT (HYbrid Single-Particle Lagrangian Integrated Trajectory) Model access via NOAA ARL READY, Tech. rep., NOAA Air Resources Laboratory, Silver Spring, MD., http://www.arl.noaa.gov/ready/hysplit4.html, 2003.

Dubovik, O., Holben, B., Eck, T. F., Smirnov, A., Kaufman, Y. J., King, M. D., Tanre, D., and Slutsker, I.: Variability of absorption and optical properties of key aerosol types observed in worldwide locations, J. Atmos. Sci., 59, 590-608, 2002.

Forster, P., Ramaswamy, V., Artaxo, P., Berntsen, T., Betts, R., Fahey, D., Haywood, J., Lean, J., Lowe, D., Myhre, G., Nganga, J., Prinn, R., Raga, G., Schulz, M., and Van Dorland, R.: Changes in Atmospheric Constituents and in Radiative Forcing. In: Climate Change 2007: The Physical Science Basis, Contribution of Working Group I to the Fourth Assessment Report of the Intergovernmental Panel on Climate Change, edited by: Solomon, S., Qin, D., Manning, M., Chen, Z., Marquis, M., Averyt, K. B., Tignor, M., and Miller, H. L., Cambridge University Press, Cambridge, United Kingdom and New York, NY, USA, 2007.

Gustafsson, O., Krusa, M., Zencak, Z., Sheesley, R. J., Granat, L., Engström, E., Praveen, P. S., Rao, P. S. P., Leck, C., and Rodhe, H.: Brown Clouds over South Asia: Biomass or Fossil Fuel Combustion?, Science, 323, 495-498, 2009.

Hansson, H., Martinsson, B., Swietlicki, E., Asking, L., Heintzenberg, J., and Ogren, J.: PIXE in complex analytical systems for atmospheric chemistry, Nucl. Instrum. Methods., 22, 235-240, 1987.

Heintzenberg, J.: A Processor-Controlled Multisample Soot Photometer, Aerosol Sci. Tech., 8, 227-233, 1988.

Hitzenberger, R., Petzold, A., Bauer, H., Ctyroky, P., Pouresmaeil, P., Laskus, L., and Puxbaum, H.: Intercomparison of thermal and optical measurement methods for elemental carbon and black carbon at an urban location, Environ. Sci. Tech., 40, 6377-6383, 2006.

Horvath, H.: Atmospheric light-absorption - a review, Atmos. Environ., 27, 293-317, 1993.

Jacobson, M.: A physically-based treatment of elemental carbon optics: Implications for global direct forcing of aerosols, Geophys. Res. Lett., 27, 217-220, 2000.

Jacobson, M.: Control of fossil-fuel particulate black carbon and organic matter, possibly the most effective method of slowing global warming, J. Geophys. Res.-Atmos., 107, 4410, doi:10.1029/2001JD001376, 2002.

Kaufman, Y., Smirnov, A., Holben, B., and Dubovik, O.: Baseline maritime aerosol: methodology to derive the optical thickness and scattering properties, Geophys. Res. Lett., 28, 3251-3254, 2001.

Kondo, Y., Sahu, L., Kuwata, M., Miyazaki, Y., Takegawa, N., Moteki, N., Imaru, J., Han, S., Nakayama, T., Oanh, N. T. K., $\mathrm{Hu}$, M., Kim, Y. J., and Kita, K.: Stabilization of the Mass Absorption Cross Section of Black Carbon for Filter-Based Absorption Photometry by the use of a Heated Inlet, Aerosol. Sci. Tech., 43, 741-756, 2009.

Lack, D. A., Cappa, C. D., Covert, D. S., Baynard, T., Massoli, P., Sierau, B., Bates, T. S., Quinn, P. K., Lovejoy, E. R., and Ravishankara, A. R.: Bias in Filter-Based Aerosol Light Absorption Measurements Due to Organic Aerosol Loading: Evidence from Ambient Measurements, Aerosol. Sci. Tech., 42, 1033-1041, 2008.

Mayol-Bracero, O. L., Gabriel, R., Andreae, M. O., Kirchstetter, T. W., Novakov, T., Ogren, J., Sheridan, P., and Streets, D. G.: Carbonaceous aerosols over the Indian Ocean during the Indian Ocean Experiment (INDOEX): Chemical characterization, optical properties, and probable sources, J. Geophys. Res., 107, 8030, doi:10.1029/2000JD000039, 2002.

Müller, T., Henzing, J. S., de Leeuw, G., Wiedensohler, A., Alastuey, A., Angelov, H., Bizjak, M., Collaud Coen, M., Engström, J. E., Gruening, C., Hillamo, R., Hoffer, A., Imre, K., Ivanow, P., Jennings, G., Sun, J. Y., Kalivitis, N., Karlsson, H., Komppula, M., Laj, P., Li, S.-M., Lunder, C., Marinoni, A., Martins dos Santos, S., Moerman, M., Nowak, A., Ogren, J. A., Petzold, A., Pichon, J. M., Rodriquez, S., Sharma, S., Sheridan, P. J., Teinilä, K., Tuch, T., Viana, M., Virkkula, A., Weingartner, E., Wilhelm, R., and Wang, Y. Q.: Characterization and intercomparison of aerosol absorption photometers: result of two intercomparison workshops, Atmos. Meas. Tech., 4, 245-268, doi:10.5194/amt-4-245-2011, 2011.

Nair, S., Parameswaran, K., and Rajeev, K.: Seven year satellite observations of the mean structures and variabilities in the regional aerosol distribution over the oceanic areas around the Indian subcontinent, Ann. Geophys., 23, 2011-2030, 2005.

Norman, M., Leck, C., and Rodhe, H.: Differences across the ITCZ in the chemical characteristics of the Indian Ocean MBL aerosol during INDOEX, Atmos. Chem. Phys., 3, 563-579, doi:10.5194/acp-3-563-2003, 2003.

Petzold, A., Schloesser, H., Sheridan, P., Arnott, W., Ogren, J., and Virkkula, A.: Evaluation of multiangle absorption photometry for measuring aerosol light absorption, Aerosol. Sci. Tech., 39, 40-51, 2005.

Quinn, P., Coffman, D., Bates, T., Miller, T., Johnson, J., Welton, E., Neususs, C., Miller, M., and Sheridan, P.: Aerosol optical properties during INDOEX 1999: Means, variability, and controlling factors, J. Geophys. Res.-Atmos., 107, 8020, doi:10.1029/2000JD000037, 2002.

Reddy, M., Boucher, O., Venkataraman, C., Verma, S., Leon, J., Bellouin, N., and Pham, M.: General circulation model estimates of aerosol transport and radiative forcing during the Indian Ocean Experiment, J. Geophys. Res.-Atmos., 109, D16205, doi:10.1029/2004JD004557, 2004.

Schnaiter, M., Gimmler, M., Llamas, I., Linke, C., Jger, C., and Mutschke, H.: Strong spectral dependence of light absorption by organic carbon particles formed by propane combustion, Atmos. Chem. Phys., 6, 2981-2990, doi:10.5194/acp-6-2981-2006, 2006. 
Sheridan, P., Arnott, W., Ogren, J., Andrews, E., Atkinson, D., Covert, D., Moosmuller, H., Petzold, A., Schmid, B., Strawa, A., Varma, R., and Virkkula, A.: The Reno Aerosol Optics Study: An evaluation of aerosol absorption measurement methods, Aerosol. Sci. Tech., 39, 1-16, 2005.

Stohl, A.: Computation, accuracy and applications of trajectories a review and bibliography, Atmos. Environ., 32, 947-966, 1998.
Stumm, W. and Morgan, J.: Aquatic chemistry, John Wiley \& Sons, New York, 780 pp, 1981.

Subramanian, R., Roden, C. A., Boparai, P., and Bond, T. C.: Yellow beads and missing particles: Trouble ahead for filterbased absorption measurements, Aerosol. Sci. Tech., 41, 630637, 2007. 